\title{
Solid-state chemistry and polymorphism of the
}

\section{nucleobase adenine}

Tomislav Stolar, ${ }^{1,}$ Stipe Lukin, ${ }^{1,+}$ Josip Požar, ${ }^{1}$ Mirta Rubčić, ${ }^{1}$ Graeme M. Day, ${ }^{2}$ Ivana Biljan, ${ }^{1}$ Dubravka Šišak Jung, ${ }^{3}$ Gordan Horvat, ${ }^{1}$ Krunoslav Užarević, ${ }^{4}$ Ernest Meštrović, ${ }^{1,5 *}$ and Ivan Halasz ${ }^{4 *}$

${ }^{1}$ Department of Chemistry, Faculty of Science, University of Zagreb, Horvatovac 102a, 10000 Zagreb, Croatia

${ }^{2}$ School of Chemistry, University of Southampton, Southampton, United Kingdom

${ }^{3}$ DECTRIS Ltd. Taefernweg 1, 5405 Baden-Daettwil, Switzerland

${ }^{4}$ Ruđer Bošković Institute, Bijenička cesta 54, HR-10000 Zagreb, Croatia

${ }^{5}$ PLIVA Croatia Ltd. Research and Development, Prilaz baruna Filipovića 29, 10000 Zagreb, Croatia

$\$$ These authors contributed equally to this work.

Email: ernest.mestrovic@pliva.com; ivan.halasz@irb.hr 


\section{ABSTRACT}

The nucleobase adenine plays a pivotal role in the chemistry of life, but is also becoming increasingly interesting as a building block in the synthesis of functional solid materials. Although commercially available as a solid, adenine's solid-state chemistry has so far been neglected. In this comprehensive study it is shown that adenine is most often marketed as a mixture of two polymorphs, one previously known, and a new polymorph. Both polymorphs exhibit layered structures with different hydrogen-bonding patterns within layers. The crystal structure of the new polymorph was elucidated using synchrotron powder X-ray diffraction. Polymorph occurrence conditions, interconversion and the difference in their thermodynamic stability were established theoretically and experimentally revealing the polymorph with $Z^{\prime}=2$ (known) as stable relative to the polymorph with $Z^{\prime}=1$ (new). The adenine layers in both polymorphs are connected by weak interaction likely resulting in stacking faults which are manifested in anisotropic line broadening of their powder diffraction patterns. Analysis of a few commercial samples of adenine revealed them all to be a polymorph mixture, which could be inconvenient in experiments where properties of the solid material could be relevant.

\section{INTRODUCTION}

Adenine belongs to the fundamental molecules of life. As one of the five nucleobases, it plays a pivotal role in nucleotide pairing of the two DNA strands as well as in ribosomal protein synthesis, by being directly involved in supramolecular recognition during protein synthesis. ${ }^{1}$ Naturally, there has been a tremendous interest in the chemistry of adenine which remained for the most part focused on its solution behavior, while 
leaving its solid-state chemistry largely unexplored. Even though there are numerous examples of supramolecular entities or metal-organic systems comprising adenine as a building block, ${ }^{2}$ little is known on the solid-state chemistry of adenine itself.

In addition to its numerous hydrogen-bond donor and acceptor groups, adenine's potential to build various supramolecular networks is further broadened by the possibility of forming tautomers, the so-called, $7 \mathrm{H}$ and $9 \mathrm{H}$ tautomers (Scheme 1). ${ }^{3}$ Recent studies also predict that crystalline adenine, along with the four other nucleobases, should be a wide gap semiconductor for electrons moving along the nucleobases' stacking direction. ${ }^{4}$ These observations warrant a comprehensive study of chemical and physical properties of solid adenine, but also of other solid nucleobases.

The inability to unveil the crystal structure of adenine has likely been related to the problematic preparation of its fine-quality single crystals by common crystallization methods. In 2008, single-crystals of adenine were successfully obtained by sublimation in a custom designed apparatus, ${ }^{5}$ allowing its crystal structure to be finally determined as the last among the five nucleobases. ${ }^{6}$ However, advances in powder X-ray diffraction (PXRD) now offer new opportunities regarding crystal structure elucidation, where obtaining a single-crystal is no longer imperative. This is illustrated by the case of Llysine, ${ }^{7}$ the last naturally occurring amino acid to have its crystal structure solved based on PXRD, as well as D-ribose, which resisted structural characterization for decades until its crystal structure was unveiled using PXRD data. ${ }^{8}$ Also, after a century of research and use, the first insight into the structure of solid bismuth salicylates, which are relevant for the chemistry of the over-the-counter drug Pepto-Bismol, was also obtained from PXRD data. $^{9}$ 
In this work, while attempting to achieve solid-state supramolecular recognition 10 between complementary nucleobases by employing mechanochemistry, we came to realize that the powder X-ray diffraction (PXRD) pattern of a commercial batch of adenine which we had at hand could not be correlated with its crystal structure known at that time. ${ }^{5}$ This observation prompted us to investigate the solid-state chemistry of adenine in greater detail. Indeed, the commercial batch we examined proved to be a mixture of two polymorphs, one corresponding to the previously known form ${ }^{5}$ (to which we refer here as polymorph I) and the other representing a new form (polymorph II), both comprising the $9 \mathrm{H}$ tautomer of adenine (Scheme 1). In this comprehensive study we report the crystal structure of the new polymorph, which was elucidated from synchrotron PXRD data, and assessment of occurrence conditions for the two polymorphs as well as the difference in their thermodynamic stability. Polymorphism of nucleobases is here observed for the second time, after recently being discovered for cytosine. 11

Scheme 1. Molecular structure of the $9 \mathrm{H}$ tautomer of adenine with numbering of ring nitrogen atoms.

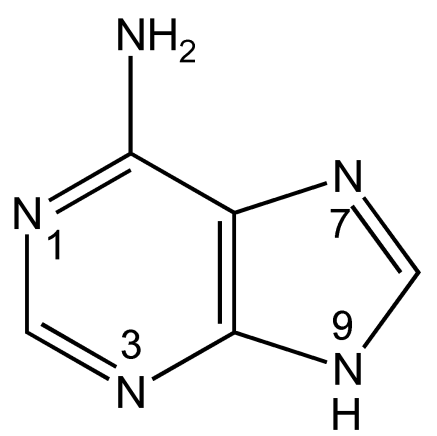




\section{EXPERIMENTAL}

Polymorph resolution. In order to prepare pure polymorphs I and II, the commercial sample (Fluka, Analysis Number: $312647 / 1$ 592; purity $>99.5 \%$ ), corresponding to a mixture of two polymorphs was used. Polymorph II was prepared by recrystallization, where the mixture was dissolved in boiling 50\% ethanol, and the solution was allowed to cool slowly to room temperature. Pure polymorph I was prepared by keeping the commercial batch suspended in $50 \%$ ethanol in a sonic bath for several hours, depending on the amount of the initial material. Alternatively, polymorph I was obtained from slurry in water at room temperature. However, this synthetic procedure required a longer period of time. For example, $100 \mathrm{mg}$ of the commercial batch required around three weeks of stirring in water at room temperature to fully transform to the polymorph I.

Powder X-ray diffraction patterns in this study were collected at the European Synchrotron Radiation Facility (ESRF), the Swiss Light Source (SLS) as well as on a laboratory diffractometer, all at room temperature. For the purpose of crystal structure determination of polymorph II, the powder diffraction pattern was collected at the highresolution powder diffraction beamline ID31 (now moved to ID22) at the ESRF, using the radiation wavelength of $0.39982 \AA$. First, peak positions of 21 well resolved reflections were used to index the diffraction pattern which yielded an orthorhombic unit cell $\left(a=8.419(2) \AA, b=22.531(2) \AA, c=12.7580(2) \AA, V=2420.0(7) \AA^{3}\right)$ with likely $F$ centering according to systematic extinctions. Unit cell of this volume can accommodate 16 molecules of adenine. Based on possible systematic extinctions, the space group Fddd can fit the pattern in a Pawley refinement. However, the general position in this space 
group repeats itself 32 times and could not accommodate adenine molecules without imposing disorder. We have therefore tested its subgroups with the same systematic extinctions: $F d d 2, F d 2 d$ and $F 2 d d$. With the given choice of unit cell axes, only the $F d d 2$ space group yielded a chemically meaningful and ordered crystal structure. The crystal structure was solved by simulated annealing in direct space, treating the molecule of adenine as a rigid body. An initial molecular model was constructed using the (known) molecular structure of adenine from polymorph I. Highly accurate refinement of crystal structure of adenine polymorph II was hindered by two factors: resolution of the collected data $\left(d_{\min }=1.43 \AA\right)$ and data quality (data statistics, shape of the background). The first factor required that the Rietveld refinement be carried out using a rigid-body approach, while the second hindered the possibility to examine (or describe) possible disorder in the material using difference Fourier maps. For this reason, the description of adenine structure was limited to an idealized crystal structure. The final Rietveld refinement $\left(R_{\exp }\right.$ $\left.=4.62 \%, R_{\mathrm{wp}}=7.88 \%, R_{\mathrm{p}}=6.10 \%, g o f=1.71\right)$ included unit cell parameters, zero error, peak shape parameters, background parameters and rigid-body parameters (Figure 1).

The powder diffraction pattern had anisotropic peak broadening which was empirically described using spherical harmonies function applied to Lorentzian peak widths. We notice that anisotropy in peak widths can be correlated with the crystal structure (see later). Peaks in the class ( $h k 0)$ and class ( $h k l)$ are broad while e.g. peak 004 is very narrow. Indeed, the layered crystal structure of polymorph II has layers parallel to the $(a, b)$ plane. Such peak broadening suggests sliding of layers and some degree of disorder in layer to layer arrangement. 
Some disparities between the calculated and measured patterns could be observed. First, peaks corresponding to 004 and 040 reflections were found to exhibit more intensity than could be calculated from the structure model. Second, peaks in $h k 0$ and some $h k l$ reflection classes were found to be broader than peaks of the rest of the pattern, which was empirically described using spherical harmonics function applied to Lorentzian peak widths. These two effects can be a consequence of crystallite size (and morphology) and stacking faults in the crystal. As the deconvolution of these two factors requires extensive profile analysis, only simplified considerations are mentioned in this work (see Results and discussion).

All calculations were performed using the program TOPAS12. The crystal structure of polymorph II, including the original diffraction data, has been deposited with the Cambridge Crystallographic Data Center (CCDC) under the number CCDC 1443169. The data can be retrieved free-of-charge under http://www.ccdc.cam.ac.uk/getstructures.

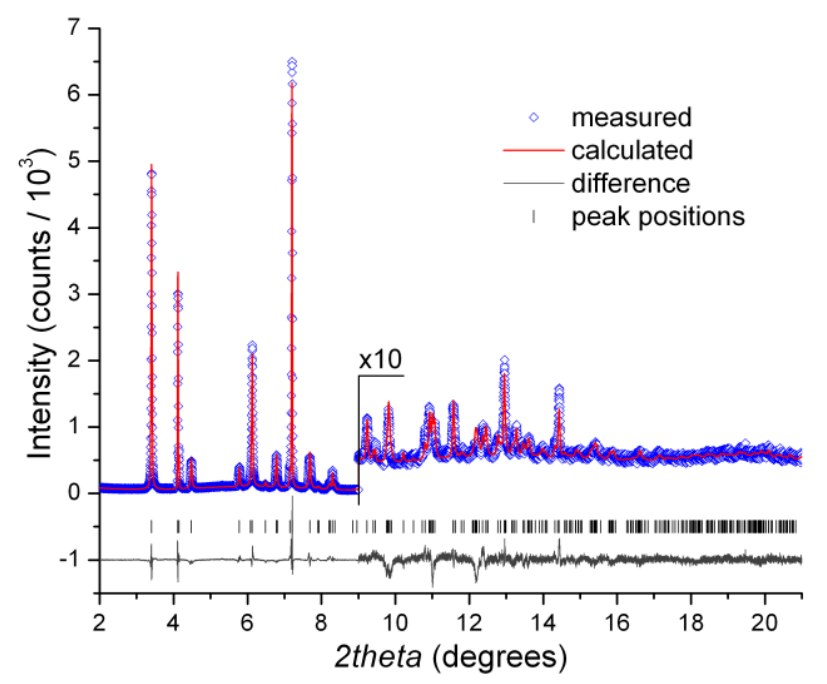

Figure 1. Rietveld refinement plot of polymorph II of adenine on a diffraction pattern collected at the high-resolution powder diffraction beamline ID31 (now ID22) at the 
ESRF using radiation of wavelength of $0.39982 \AA$. The high angle part is enlarged 10 times to reveal more detail.

The pattern of the commercial batch of adenine was collected at the Material Science beamline at the Swiss Light Source (SLS) ${ }^{13}$ using radiation of wavelength of $1.00000 \AA$ A. It was modeled using the Rietveld method as the mixture of polymorphs I and II with the weight fractions: $w$ (polymorph I) $=24 \%$ and $w$ (polymorph II) $=76 \%$ (Figure 2).

Solid state NMR spectroscopy. The ${ }^{13} \mathrm{C}$ and ${ }^{15} \mathrm{~N}$ CP-MAS NMR spectra of adenine polymorphs I and II were recorded on an Agilent Technologies NMR System $600 \mathrm{MHz}$ NMR spectrometer equipped with a $3.2 \mathrm{~mm}$ NB Double Resonance HX MAS Solids Probe. The Larmor frequencies of carbon and nitrogen nuclei were 150.77 and 60.78 $\mathrm{MHz}$, respectively. The ${ }^{13} \mathrm{C}$ and ${ }^{15} \mathrm{~N}$ CP-MAS NMR spectra were externally referenced using hexamethylbenzene (HMB) and ammonium sulfate ( $\delta=-355.7 \mathrm{ppm}$ with reference to nitromethane at $\delta=0.0 \mathrm{ppm}$, respectively). Samples were spun at the magic angle with $16 \mathrm{kHz}$ during ${ }^{13} \mathrm{C}$ measurement and with $10 \mathrm{kHz}$ during ${ }^{15} \mathrm{~N}$ measurement.

Lattice energy calculations. The crystal structures of both polymorphs were lattice energy minimized, allowing for flexibility of the molecular geometry, using an energy model that combines anisotropic atom-atom potentials for intermolecular interactions with a density functional theory (DFT) evaluation of the molecular geometry and intramolecular energy. During the course of optimization, unit cell parameters, molecular positions and orientations, all intramolecular angles and dihedrals involving polar $(\mathrm{H}-\mathrm{N})$ hydrogen atoms were allowed to relax in response to intermolecular interactions in the 
crystal. Lattice energy minimizations were performed using the CrystalOptimizer software ${ }^{14}$ calling Gaussian0915 for DFT molecular electronic structure calculations and DMACRYS16 for model potential-based intermolecular energy calculations.

Intermolecular energies were calculated using a revised version of the W9917 exp-6 atom-atom potential, combined with atomic multipoles (up to hexadecapole on all atoms), calculated from a distributed multipole analysis 18 of a B3LYP/6-311G(d,p) charge density. Intramolecular energies were also evaluated at the B3LYP/6-311G(d,p) level of theory. Charge-charge, charge-dipole and dipole-dipole interactions were summed using Ewald summation, while all higher order electrostatics and repulsiondispersion (exp-6) interactions were summed to a direct space $30 \AA$ cutoff. Following this initial lattice energy minimization, a second, rigid-molecule lattice energy minimization was performed using atomic multipoles obtained from DFT calculations that were carried out within a polarizable continuum model with $\varepsilon=3.0$. This continuum model was used in these calculations to incorporate the approximate effects of molecular polarization within lattice energy calculations on molecular crystals. 19

Free energies of the polymorphs were assessed using harmonic, rigid-molecule lattice dynamics to evaluate the phonon density of states. ${ }^{20}$ Reciprocal space was sampled using a series of supercells chosen to sample phonon frequencies within the first Brillouin zone to a maximum separation of $0.08 \AA^{-1}$. Detailed procedures and algorithms of the methods used can be found elsewhere. 21

Thermodynamic stability analysis. The difference in polymorph stabilities at $25{ }^{\circ} \mathrm{C}$ was determined using ultraviolet spectrophotometry (UV), by means of a Varian Cary 5 spectrophotometer equipped with a thermostatting device. Suspensions of each solid were 
prepared in phosphate buffer with the $\mathrm{pH}$ adjusted to 12.5. This assured that the deprotonated adenine is dominant in the prepared supernatants $\left(\mathrm{pK}_{2}=9.4\right) .{ }^{22}$

The suspension of polymorph I was stirred for several days at $25^{\circ} \mathrm{C}$. The solid was then allowed to settle and an aliquot of the saturated solution was taken and diluted to an appropriate concentration. UV spectra of accordingly prepared solutions were recorded.

A slightly different experimental approach was used for determining the solubility of the metastable polymorph II in order to prevent its transformation to polymorph I. A relatively large excess of the solid was added to the buffer solution and stirred vigorously for half an hour, an hour and for two hours. The resulting suspensions were then centrifuged $(10000 \mathrm{~g})$, and the aliquots of supernatants were taken for UV measurements. In order to determine whether the conversion of polymorph II to a more stable polymorph I during the specified time periods had occurred, the powder X-ray diffraction patterns of the solids were recorded immediately after centrifugation. The absorbance at $265 \mathrm{~nm}$ was used to determine the adenine concentration in the supernatants. The molar absorbance coefficient of deprotonated adenine at the specified wavelength $\left(\varepsilon_{265}=12174 \mathrm{dm}^{3} \mathrm{~mol}^{-1} \mathrm{~cm}^{-1}\right)$ was obtained by measuring the absorbance of solutions of known concentrations.

Thermal analysis. Differential scanning calorimetry (DSC) experiments were performed using the Mettler-Toledo DSC823e calorimeter in the temperature range from 25 to $400{ }^{\circ} \mathrm{C}$. Thermogravimetric (TG) measurements were carried out on the MettlerToledo TGA/SDTA851e thermobalance. Preliminary TG measurements were performed in the temperature range from 25 to $600{ }^{\circ} \mathrm{C}$ with the heating rate of $5{ }^{\circ} \mathrm{C} \mathrm{min}^{-1}$ (Figures S1 and S2). More detailed measurements were achieved by using various heating regimes 
and in different temperature ranges (for details see SI, Figures S3-S5). All measurements were conducted under a steady nitrogen stream using aluminum crucibles (40 $\mu \mathrm{L})$. Data collection and analysis was performed using the program package STARe Software 9.01 .23

\section{RESULTS AND DISCUSSION}

Isolation and identification of new solid forms of a specific compound, i.e. new polymorphs, 24 continues to be a vital area of research in solid-state chemistry. 25 The way individual molecules recognize each other and assemble to form specific crystal architecture has an enormous impact on fundamental understanding of the processes related to nucleation and crystal growth. $24^{\mathrm{d}, 25 \mathrm{a}} 26$ In the context of new materials, different polymorphs of a substance may possess considerably different physicochemical properties. $^{27,28}$ Consequently, there has been much interest in the pharmaceutical and materials industry in intellectual protection and commercialization of particular solid forms, ${ }^{29}$ which has resulted in identification of numerous new polymorphic forms.30

From the commercial adenine polymorph mixture, each of the two polymorphs was isolated as a pure phase. The crystal structure of the unknown polymorph (II) was elucidated from powder X-ray diffraction data, which in turn allowed quantification of the commercial adenine samples via Rietveld refinement (Fig. 2). Crystal structures of polymorphs I and II are described in the following sections, and the quantitative analysis of the initial commercial sample resulted in $c a .76 \%$ of polymorph II and $c a .24 \%$ of polymorph I and is depicted on Figure 2. 
Having a commercial batch that exhibits chemical but not phase purity may cause problems if such a sample of solid adenine is used in an experiment where properties of the solid are important. We have therefore analyzed a few other commercial samples from different manufacturers. All tested commercial samples were found to be mixtures of the two polymorphs in different ratios (Figure 2, S6-S9). Moreover, Guru Row and coworkers, who published the crystal structure of the polymorph I, also had the polymorph mixture as the starting sample of adenine, as evident from a visual inspection of the powder X-ray diffraction pattern disclosed in the paper, from which they prepared polymorph I by sublimation. ${ }^{5}$ The authors have pointed out that the poor diffraction pattern resolution was limiting any attempts of structure solution from powder diffraction data of the original sample. We wish to amend to this statement that researchers who have tried to solve the adenine crystal structure from powder diffraction data, have likely worked with a mixture of the two polymorphs and that this could have been a more limiting factor for structure solution than the low diffraction pattern resolution. The distinguishing feature of a polymorph mixture diffraction pattern is the set of three close (or overlapping) diffraction peaks as the first reflections in the pattern. While polymorph I has two peaks of similar intensities, polymorph II has one reflection at a similar position in its PXRD pattern (Figure 2, inset). Details about quantitative analysis of a few commercial samples can be found in Supplementary Information (Figures S6-S9). 


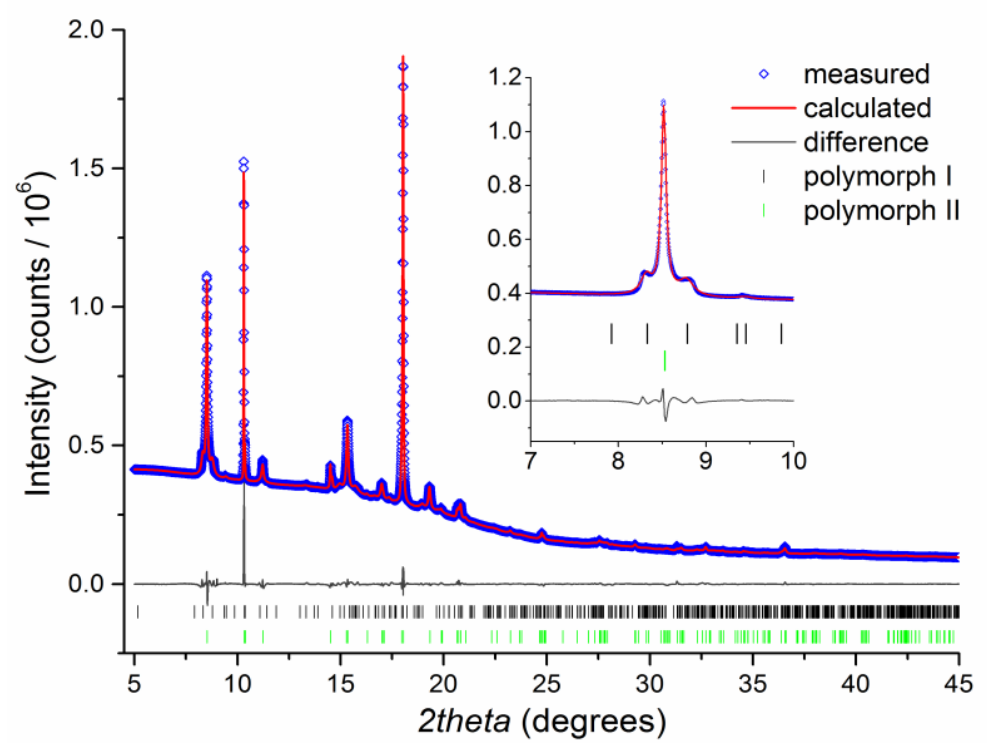

Figure 2. Rietveld refinement plot of the commercial sample from Fluka comprising two adenine polymorphs. The sample was measured at the SLS, using radiation wavelength of $1.0000 \AA$. The inset shows the low angle region of the pattern where the peaks corresponding to polymorph I can be seen as shoulders to the peak of polymorph II.

In the crystal structures of both polymorphs adenine molecules are found in the $9 \mathrm{H}-$ tautomeric form (Scheme 1), and are essentially planar, offering an assortment of good hydrogen bond donors and acceptors. Polymorph I crystallizes in the monoclinic $P 2_{1} / c$ space group with two adenine molecules in the asymmetric unit. Since each adenine molecule has three possible hydrogen-bond donors, six non-equivalent hydrogen bond donor groups occupy the asymmetric unit. Using the graph-set notation, ${ }^{31}$ these six hydrogen bonds generate six motifs at the unitary level which are all of the D type. Polymorph II of adenine crystallizes in the non-centrosymmetric orthorhombic $F d d 2$ space group and has one molecule in the asymmetric unit forming a layered structure over the network of hydrogen bonds (Figure 3a). Adenine molecules within a layer are 
related by second order rotation axes, leading to three ring motifs at the unitary level which generate three homosynthons (Figure 3a, Table 1). Two $\mathrm{R}_{2}^{2}(8)$ motifs are formed by hydrogen bonds, $\mathrm{N} 9-\mathrm{H} \cdots \mathrm{N} 3$ (green area in Figure 3a, labeled $\mathbf{a}$ in Table 1) and N2$\mathrm{H} \cdots \mathrm{N} 1$ (yellow area in Figure 3a, labeled with $\mathbf{b}$ ) whereas the $\mathrm{R}_{2}^{2}(10)$ motif is formed by the N2-H $\cdots \mathrm{N} 7$ hydrogen bond (red area in Figure 3a).
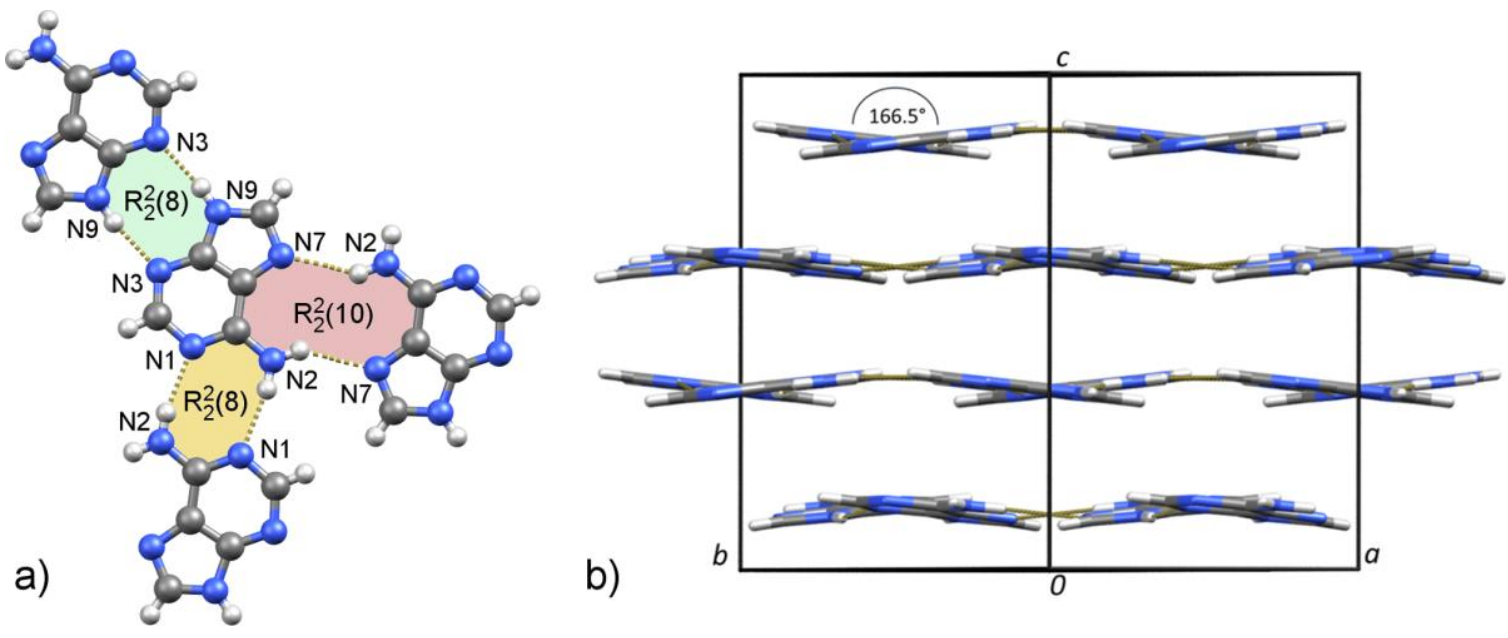

Figure 3. a) Hydrogen-bond pattern around a single adenine molecule of polymorph II, and b) layered structure of polymorph II presented along the $a b$ diagonal. The shortest distance between the layers is $\approx 3.4 \AA$, without any directional non-covalent interactions observed between adjacent layers.

Polymorph I, on the other hand, has two adenine molecules in the asymmetric unit, resulting in the formation of one homosynthon and one heterosynthon. Homosynthon pattern $R_{2}^{2}(8)$ is generated by hydrogen bonds a and d, and heterosynthon $R_{2}^{2}(9)$ features pairs of hydrogen bonds $\mathrm{b}$ and $\mathrm{f}$ as well as hydrogen bonds $\mathrm{c}$ and $\mathrm{e}$. The ring homosynthon $\mathrm{R}_{2}^{2}(8)$ is found in both polymorphs of adenine and is designated here as homosynthon A (Fig. 4a,b). It involves a hydrogen-bonded dimer employing the nitrogen 
N9 donor group and the nitrogen $\mathrm{N} 3$ acceptor, highlighted in green in Figure 3. A previous theoretical study indicated that among various ways in which two adenine molecules could connect via hydrogen bonds, the homosynthon A is the most stable dimer.32 In polymorph I this homosynthon is generated by two crystallographically independent hydrogen bonds (denoted as a, $\mathrm{d}$ in Fig. 3a) and its $\mathrm{R}_{2}^{2}(8)$ graph-set descriptor is to be found at the binary level (Table 1). In polymorph II on the other hand, homosynthon A is found at the unitary level in graph-set notation.

Packing within layers in the two crystal structures can be understood on the basis of Figs. $4 \mathrm{a}$ and $4 \mathrm{~b}$, where the two-molecule assembly of the homosynthon $\mathrm{A}$ in polymorph I has alternating orientations, while in polymorph II it always retains the same orientation. The layers are corrugated with neighboring adenine molecules tilted by approximately 13 degrees $\left(13.1^{\circ}\right.$ in polymorph I and $13.4^{\circ}$ in polymorph II, Figure $3 \mathrm{~b}$ ) relative to each other. Structures of both polymorphs are characterized also by the lack of directional noncovalent interactions between layers, which are stabilized by van der Waals forces and stacked one above the other with an interlayer distance of ca. $3.4 \AA$ (Figures $3 b, 4 c$ and S10). Theoretically, this packing arrangement can open up a possibility of stacking faults in layers of adenine throughout the crystal. In a very simplified manner, this theory can be brought into correlation with specific features observed in a measured powder pattern of polymorph II. Absence of strong interactions between the layers could result in shifted and/or rotated layers, especially during a fast growth of adenine crystals in the $c$ direction. Such a disorder could be reflected as anisotropic peak broadening of $h k 0$ and (certain) $h k l$ lines, and occurrence of too intense 004 and 040 peaks. The extent of disorder in a material, that could be tolerated before the structure suffers polymorphic 
transition, cannot be easily foreseen, as it depends on both thermodynamic and kinetic parameters of such a process. Moreover, a possible presence of an amorphous phase in the sample cannot be fully excluded.

These issues of the potential lack of strict three-dimensional periodicity and defects in the crystal structures bring to mind the concept of 'structural purity' raised recently by Coquerel. ${ }^{33}$ However, no real crystal is ever perfect and one can imagine a continuous change in short-range and long-range order from an amorphous state of matter, to it being a perfect single crystal. ${ }^{34}$ Modeling of deviations from strict periodicity and its effect on thermodynamic and scattering properties of adenine polymorphs is however, outside the scope of this work.

The lack of investigations concerning the structure and properties of solid adenine is in contrast to rather extensive studies of the self-assembly of adenine on surfaces.35 Briefly, two-dimensional adenine layers grown on graphite surface assumed the structure as within the layers of the stable polymorph I,36 regardless of whether such a sample was prepared by sublimation or deposited from solution. However, Mamdouh et al. found that self-assembly of adenine on graphite from 1-octanol solution results concomitantly in adenine layers as found in both polymorphs I and II.37 These authors also predicted additional ways of adenine self-assembly in two dimensions that are all similar in energy, which leaves room for the discovery of further adenine polymorphs.

Table 1. Hydrogen bonding motifs in graph-set notation for adenine polymorphs I and II. Unitary motifs are on the diagonal while binary are off the diagonal. Hydrogen bonds a-f for polymorph I and a-c for polymorph II are depicted in Fig 3. The graph-set descriptor 
of the characteristic homosynthon $\mathrm{A}$ is formed by hydrogen bonds a and $\mathrm{d}$ for polymorph I, and by the hydrogen bond a in polymorph II.

\begin{tabular}{|l|l|l|l|l|l|l||l|l|l|l|}
\hline \multicolumn{9}{|c|}{ Polymorph I, H-bonds } & \multicolumn{3}{|c|}{ Polymorph II, H-bonds } \\
\hline & a & b & c & d & e & f & a & b & c \\
\hline a & D & & & & & & a & $\mathbf{R}_{2}^{2}(\mathbf{8})$ & & \\
\hline b & $\mathbf{C}_{2}^{2}(\mathbf{1 1}$ & D & & & & & b & $\mathbf{C}_{2}^{2}(\mathbf{1 0})$ & $\mathbf{R}_{2}^{2}(\mathbf{8})$ & \\
\hline c & $\mathbf{C}_{2}^{2}(\mathbf{1 0}$ & $\mathbf{C}_{2}^{2}(\mathbf{7})$ & D & & & & c & $\mathbf{C}_{2}^{2}(\mathbf{1 0})$ & $\mathbf{C}_{2}^{2}(\mathbf{7})$ & $\mathbf{R}_{2}^{2}(\mathbf{1 0})$ \\
\hline d & $\mathbf{R}_{2}^{2}(\mathbf{8})$ & $\mathbf{C}_{2}^{2}(\mathbf{1 0}$ & $\mathbf{C}_{2}^{2}(\mathbf{1 2}$ & D & & & & & & \\
\hline e & $\mathbf{C}_{2}^{2}(\mathbf{1 0}$ & $\mathbf{C}_{2}^{2}(\mathbf{1 0}$ & $\mathbf{R}_{2}^{2}(\mathbf{9})$ & $\mathbf{C}_{2}^{2}(\mathbf{1 1}$ & $\mathbf{D}$ & & & & & \\
\hline f & $\mathbf{C}_{2}^{2}(\mathbf{1 2}$ & $\mathbf{R}_{2}^{2}(\mathbf{9})$ & $\mathbf{C}_{2}^{2}(\mathbf{8})$ & $\mathbf{C}_{2}^{2}(\mathbf{1 0}$ & $\mathbf{C}_{2}^{2}(\mathbf{7})$ & $\mathbf{D}$ & & & & \\
\hline
\end{tabular}



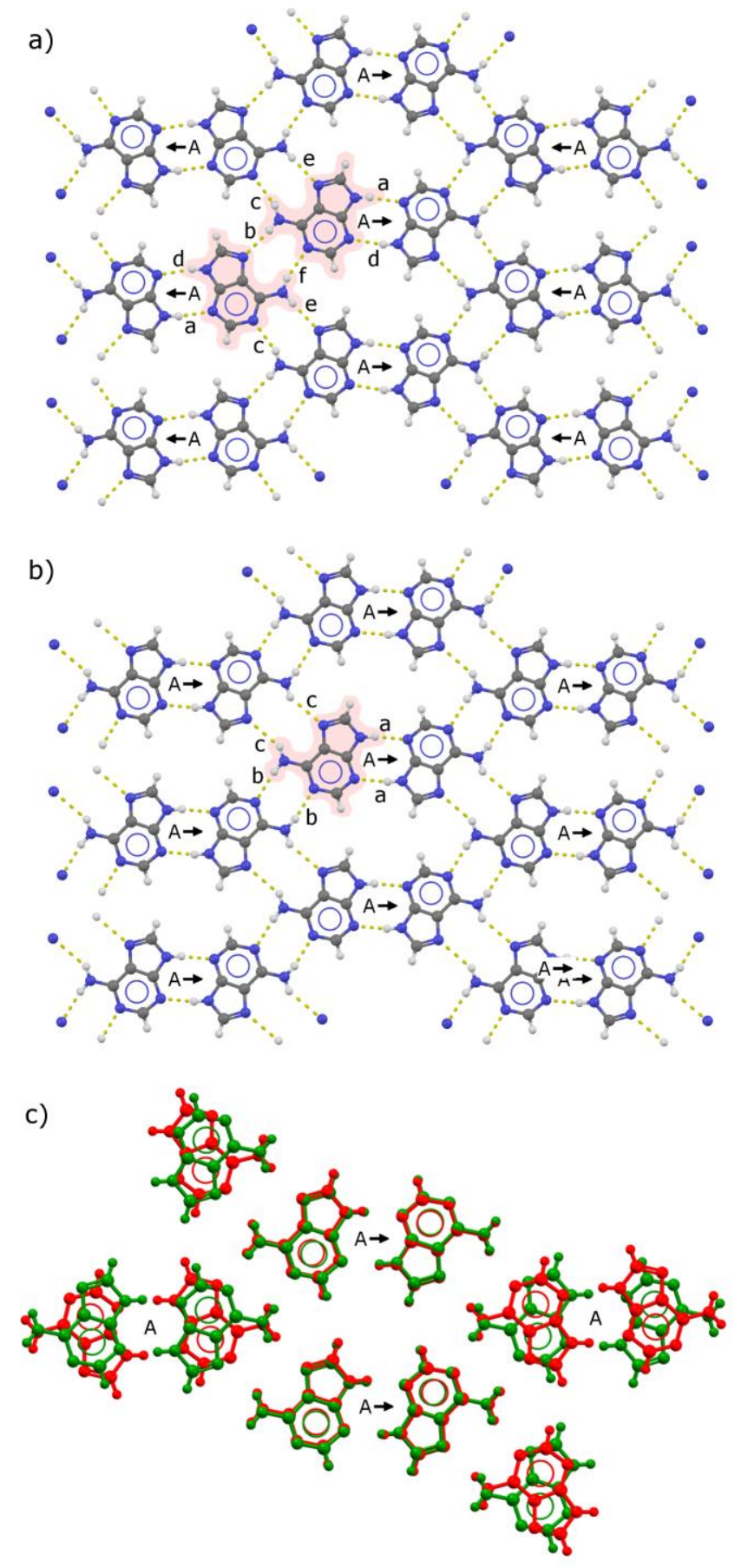

Figure 4. Hydrogen bonding in (a) polymorph I and (b) polymorph II. Hydrogen-bonding patterns are listed in Table 1 using graph-set notation. Symmetry independent molecules in each polymorph are shown on a grey background. Orientations of the homosynthon A 
are illustrated with arrows. (c) Overlay of packing within layers in polymorphs I (red) and II (green) highlighting similar periodicities within layers in the two polymorphs.

In support of the solved crystal structure of polymorph II are the almost identical solidstate ${ }^{13} \mathrm{C}$ and ${ }^{15} \mathrm{~N}$ CP-MAS NMR spectra of the two polymorphs (Figures S11-S14). No additional signals for atoms in crystallographically independent molecules could be observed in solid-state NMR spectra of polymorph I. Close similarity of infrared spectra of the two polymorphs indicates also the presence of the same tautomeric form in both polymorphs (Figure S15) which is consistent with recently described weak coupling between the intermolecular and intramolecular vibrations in solid adenine. 38

According to DSC and TG measurements, neither of the adenine polymorphs undergoes any transformation prior to $c a 250{ }^{\circ} \mathrm{C}$ (Figures S1 and S2). In the temperature region, from $c a 250{ }^{\circ} \mathrm{C}$ up to $c a 330{ }^{\circ} \mathrm{C}$, solid-state transformation of polymorph I to polymorph II is accompanied by sublimation of the sample, as evidenced by a significant weight loss in the corresponding TG curve (Figure S3). Further heating of the sample features a sharp endotherm on a DSC curve corresponding to sample degradation. Similarly, polymorph II undergoes sublimation in the temperature range from $c a .250{ }^{\circ} \mathrm{C}$ up to $c a .330^{\circ} \mathrm{C}$ (Figure S4), and it decomposes upon further heating (Figure S5).

The thermodynamic relationship between the two polymorphs was assessed experimentally as well as by theoretical lattice energy calculations. One of the proposed ${ }^{39}$ (and widely $\operatorname{argued}^{40}$ ) measures for determining the relative stability among polymorphic phases is related to the number of independent molecules in the asymmetric unit (the $Z$ ' number). It was stated that the structure with $Z^{\prime}=1$ should be thermodynamically more 
stable. However, the growing body of evidence strongly suggests that a significant number of polymorphic solids deviate from this rule, either by not having a polymorph with $Z^{\prime}=1$ or by having a thermodynamically stable polymorph with $Z^{\prime}>1 .^{41,25 a, 25^{\mathrm{g}} \mathrm{In}}$ the case of adenine, the analysis of $Z$ ' would, erroneously, imply that the newly discovered phase, polymorph II, is thermodynamically more stable.

The identification of proper polymorphic forms is especially important in pharmaceutical industry, where the metastable form of a drug can transform to a more stable polymorph upon storage or handling. Polymorphic transformations in such instances may have a tremendous impact on the related intellectual rights or the physical and chemical behavior of the drug, as was described in several cases, such as in the famous case of the Ritonavir drug. $29^{\mathrm{f}, 25 \mathrm{~h}}$

Slurry experiments, ${ }^{42}$ which are among the most widely used tools in determining the stable polymorphic form, rely on slight differences in solubility of different polymorphs (stable polymorph being the least soluble). Herein, it resulted with the formation of the pure polymorph I from aqueous slurry of the commercial batch which contained both polymorphs, stirred vigorously at room temperature (Figure S16). This finding is in agreement with calculated lattice energies of $-126.38 \mathrm{~kJ} \mathrm{~mol}^{-1}$ for polymorph I and $-122.64 \mathrm{~kJ} \mathrm{~mol}^{-1}$ for polymorph II. This $3.74 \mathrm{~kJ} \mathrm{~mol}^{-1}$ difference in lattice energies favoring polymorph I is reduced slightly by the inclusion of dynamical contributions to the free energy, since polymorph II is found to have slightly higher vibrational entropy. The difference in the molar Helmholtz energies of polymorphs II and I calculated at 300 $\mathrm{K}$ lattice energy is $3.19 \mathrm{~kJ} \mathrm{~mol}^{-1}$. One should also keep in mind that calculations were 
performed assuming fully ordered crystal structure while anisotropic peak broadening in the diffraction pattern suggests faults in stacking of layers.

The difference in polymorph stabilities at $25^{\circ} \mathrm{C}$ was also assessed experimentally. For this purpose the concentrations of the saturated solutions of both solids at $\mathrm{pH}=12.5$ were determined. This was possible since the equilibrium between the solid phase of polymorph II and adenine in solution was established rapidly (experimental section), that is, before the time needed for polymorph II to convert to polymorph I. Namely, the spectra of the supernatants obtained from suspensions mixed for half an hour were practically identical to those obtained from suspensions that were mixed for an hour. In addition, the adenine solid present in suspensions was in all cases pure polymorph II as determined by PXRD. In contrast, traces of polymorph I were observed in the remaining solid after mixing the suspensions for two hours. Accordingly, the concentration of the adenine solution in equilibrium with the polymorph II $\left(c_{\mathrm{S}}(\mathrm{II}) \pm \mathrm{SE}=(0.125 \pm 0.001) \mathrm{mol}\right.$ $\mathrm{dm}^{-3}$ ) was determined as an average value of the solution concentrations after half an hour and one hour of mixing. SE denotes the standard error of the mean.

The determination of the poymorph I stability was more straightforward (described in the experimental section). The concentration of the saturated solution at $298 \mathrm{~K}$, obtained during four independent measurements equaled $c_{\mathrm{S}}(\mathrm{I}) \pm \mathrm{SE}=(0.0796 \pm 0.008) \mathrm{mol} \mathrm{\textrm {dm } ^ { - 3 }}$. From the solubilities, standard reaction Gibbs energies for the dissolution of polymorphs can be calculated:

$$
\begin{aligned}
& \text { Adenine }(\mathrm{s}, \mathrm{I}) \rightleftarrows \text { Adenine }(\mathrm{s} \ln .) \\
& \Delta_{\mathrm{s}} G^{\circ}(\mathrm{I})=-R T \ln K_{\mathrm{s}}^{\circ}(\mathrm{I})=-R T \ln \gamma c_{\mathrm{s}}(\mathrm{I})
\end{aligned}
$$


Adenine (s, II) $\rightleftarrows$ Adenine(sln.)

$\Delta_{\mathrm{s}} G^{\circ}(\mathrm{II})=-R T \ln K_{\mathrm{s}}^{\circ}(\mathrm{II})=-R T \ln \gamma c_{\mathrm{s}}(\mathrm{II})$

In the above equations $\Delta_{\mathrm{s}} G^{\circ}$ and $K_{s}{ }^{\circ}$ denote standard solution Gibbs energy and the corresponding solubility constant. Symbol $c_{\mathrm{s}}$ stands for the saturated solution concentration and $\gamma$ for the activity coefficient of the deprotonated adenine, predominant in solution. Due to equal concentrations of phosphate buffer in all supernatants and its considerable excess with respect to adenine, the activity coefficients of the adenine base can be taken as equal.

The dissolution equilibrium requires the chemical potentials of both polymorphs to be equal to that of adenine in saturated solutions:

$$
\begin{aligned}
& \mu^{\circ}(\mathrm{I})+R T \ln a(\mathrm{I})=\mu^{\circ}(\mathrm{A}, \mathrm{s} \ln )+R T \ln \gamma c_{s}(\mathrm{I}) \\
& \mu^{\circ}(\mathrm{II})+R T \ln a(\mathrm{II})=\mu^{\circ}(\mathrm{A}, \mathrm{s} \ln )+R T \ln \gamma c_{s}(\mathrm{II}) .
\end{aligned}
$$

Since the activities of both polymorph forms are equal to unity $(a(\mathrm{I})=a(\mathrm{II})=1)$ and $p$ $\approx p^{\circ}$, the difference in their standard chemical potentials corresponds to the difference in their standard molar Gibbs energies can be expressed as:

$$
\mu^{\circ}(\mathrm{II})-\mu^{\circ}(\mathrm{I})=G_{m}^{\circ}(\mathrm{II})-G_{m}^{\circ}(\mathrm{I})=R T \ln \frac{c_{s}(\mathrm{II})}{c_{s}(\mathrm{I})} .
$$


The value obtained from this analysis is $1.1 \pm 0.3 \mathrm{~kJ} \mathrm{~mol}^{-1}$ in favor of the polymorph $\mathrm{I}$, which was the stable polymorph as determined in a slurry experiment, as well as according to lattice energy calculations. The experimentally obtained Gibbs energy difference is essentially in reasonably good agreement with the calculated value, considering that typical errors in calculated lattice energies using the best current methods are expected to be on the order of a few $\mathrm{kJ} \mathrm{mol}^{-1}$. Namely, from the thermodynamic point of view, both the calculated and experimental values of the free energy difference are very small, which is typical of the energy differences between polymorphs of organic molecules. 21 Such a result is also in accord with the determined crystal structures in which similar hydrogen bonding patterns within the layers comprising both solids were observed.

The breakdown of contributions to the calculated lattice energies shows that the polymorph stability difference results from a balance between the relatively nondirectional repulsion-dispersion (van der Waals) interactions and the highly directional electrostatics. The dominant contribution to the polymorph relative stabilities is the electrostatic component of the lattice energy, which favors polymorph I by $5.4 \mathrm{~kJ} \mathrm{~mol}^{-1}$. Since electrostatics are the principal contribution to hydrogen bond energies, these results indicate that the hydrogen bonding seen in polymorph $\mathrm{I}$ is the most favorable. This electrostatic preference is slightly counter-balanced by more favorable (by $1.7 \mathrm{~kJ} \mathrm{~mol}{ }^{-1}$ ) repulsion-dispersion contributions to the lattice energy of polymorph II than polymorph I, which might relate to slightly better steric characteristics of molecular packing in polymorph II. 
Thermally induced solid state transformation between the two forms was studied by differential scanning calorimetry and thermogravimetric analysis. At higher temperatures, polymorph I irreversibly transforms into polymorph II (for details see the Experimental section and the SI). It can thus be concluded that, while polymorph I is stable at room temperature, at higher temperatures this order seems to be reversed. The calculated entropy difference $\left(S_{\text {polymorph II }}-S_{\text {polymorph I }}=1.6 \mathrm{~J} \mathrm{~mol}^{-1} \mathrm{~K}^{-1}\right.$ at $\left.300 \mathrm{~K}\right)$ relates to greater vibrational freedom (rigid molecule vibrations and librations) in polymorph II and agrees with the observed reversal of the order of stability at higher temperatures. However, the harmonic calculations applied here are not expected to predict the transition temperature accurately, which would require a more sophisticated treatment, including thermal expansion and temperature-dependence of the vibrational frequencies themselves.

Different commercial batches from various suppliers show that adenine is typically marketed as a mixture of two polymorphs indicating that they are close in energy, which was here confirmed by experiment. ${ }^{42 c, 43}$ The composition was usually in favor of polymorph II (Figures 2, S6-S9), with the exception of the ca. fifty year old batch, which contained more of polymorph I. Without the original PXRD data, it is not possible to claim whether this difference in the composition is a result of different preparation procedures or perhaps a solid-state transformation of the less stable polymorph to the stable one upon storage. 


\section{CONCLUSION}

The nucleobase adenine has had its solid-state chemistry largely neglected. Here we have established the existence of the second polymorph of adenine from a commercial batch of pure adenine. Having resolved the preparation of both polymorphs in their pure forms, their solid-state chemistry has been examined using a variety of analytical and computational techniques. The crystal structure of polymorph II was solved from PXRD data while the thermodynamic relationship between polymorphs was assessed experimentally and theoretically. Polymorph I is stable relative to polymorph II at room temperature, whereas it will irreversibly transform to polymorph II by heating.

We have analyzed several adenine samples from different suppliers and found them all to be mixtures of polymorphs of various compositions. Since polymorphs of adenine show different thermal behavior, solubility, as well as other physicochemical properties, samples of adenine which are a mixture of two phases might prove inconvenient in uses where properties of adenine as a solid might be relevant.

\section{ACKNOWLEDGEMENTS}

This work was supported by the Ministry of Science, Education and Sport of the republic of Croatia and the Ruđer Bošković Institute, Zagreb. We are grateful to Dr. Josip Bronić and Dr. Manda Ćurić (both Ruđer Bošković Institute, Zagreb) for support. We thank Prof. Janez Plavec and Dr. Primož Šket (National Institute of Chemistry, Ljubljana, Slovenia) for solid-state NMR measurements. Caroline Curfs (European Synchrotron Radiation Facility, Grenoble, France) is gratefully acknowledged for help with the PXRD 
data collection. We are grateful to Nikola Basarić, Enidija Lukša, and Biserka Žinić, (all Ruđer Bošković Institute, Zagreb), Nikola Cindro, and Rosana Ribić (both University of Zagreb) for providing commercial samples of adenine. GMD thanks the European Research Council for funding under grant ERC-StG-2012-ANGLE-307358.

\section{AUTHOR INFORMATION}

\section{Corresponding Authors}

Ivan Halasz, Ruđer Bošković Institute, Bijenička cesta 54, HR-10000 Zagreb, Croatia, Email: ivan.halasz@irb.hr

Ernest Meštrović, PLIVA Croatia Ltd. Research and Development, Prilaz baruna Filipovića 29, 10000 Zagreb, Croatia, Email: ernest.mestrovic@pliva.com

\section{REFERENCES}

1. Voet, D.; Voet, J. G., Biochemistry (4th ed.), John Wiley \& Sons Inc.: Hoboken, NJ (2011).

2. (a) Etter, M. C.; Reutzel, S. M.; Choo, C. G. J. Am. Chem. Soc., 1993, 115, 4411;(b) McHugh, C.; Erxleben, A. Cryst. Growth Des. 2011, 11, 5096; (c) Thompson, L. J.; Elias, N; Male, L.; Tremayne, M. Cryst. Growth Des. 2013, 13, 1464; (d) Fu, H.-R.; Zhang, J. Cryst. Growth Des. 2015, 15, 1210; (e) Stylianou, K. C.; Warren, J. E.; Chong, S. Y.; Rabone, J.; Bacsa, J.; Bradshaw, D.; Rosseinsky, M. J. Chem. Commun. 2011, 47, 3389; (f) Cai, H.; Li, M.; Lin, X.-R.; Chen, W.; Chen, G.-H.; Huang, X.-C.; Li D. Angew. Chem. Int. Ed. 2015, 54, 
10454; (g) Burneo, I.; Stylianou, K. C.; Rodríguez-Hermida, S.; Juanhuix, J.; Fontrodona, X.; Imaz, I.; Maspoch, D. Cryst. Growth Des. 2015, 15, 3182; (h) Thomas-Gipson, J.; Pérez-Aguirre, R.; Beobide, G.; Castillo, O.; Luque, A.; Pérez-Yáñez, S.; Román, P. Cryst. Growth Des. 2015, 15, 975; (i) ThomasGipson, J.; Beobide, G.; Castillo, O.; Fröba, M.; Hoffmann, F.; Luque, A.; PérezYáñez, S.; Román, P. Cryst. Growth Des. 2014, 14, 4019; (j) Verma, S.; Mishra, A. K.; Kumar, J. Acc. Chem. Res. 2010, 43, 79.

3. García-Terán, J. P.; Castillo, O.; Luque, A.; García-Couceiro, U.; Beobide, G.; Román, P. Dalton Trans. 2006, 902

4. Maia, Jr., F. F.; Freire, V. N.; Caetano, E. W. S.; Azevedo, D. L.; Sales, F. A. M.; Albuquerque, E. L. J. Chem. Phys., 2011, 134, 175101.

5. Mahapatra, S.; Nayak, S. K.; Prathapa, S. J.; Guru Row, T. N. Cryst. Growth Des. 2008, $8,1223$.

6. First crystal structure determination of nucleobases other than adenine. For guanine see: (a) Guille, K.; Clegg, W. Acta Crystallogr., Sect. C: Cryst. Struct. Commun., 2006, 62, o515. For thymine see: (b) Ozeki, K.; Sakabe, N.; Tanaka, J. Acta Crystallogr., Sect. B: Struct. Crystallogr. Cryst. Chem., 1969, 25, 1038. For cytosine see: (c) McClure, R. J.; Craven, B. M. Acta Crystallogr., Sect. B: Struct. Crystallogr. Cryst. Chem., 1973, 29, 1234 and (d) Barker, D. L.; Marsh, R. E. Acta Crystallogr., 1964, 17, 1581. For uracil see: (e) Stuart, R. F.; Jensen, L. H. Acta Crystallogr., 1967, 23, 1102. 
7. Williams, P. A.; Hughes, C. E.; Harris, K. D. M. Angew. Chem. Ind. Ed. 2015, 54, 3973.

8. Šišak, D.; McCusker, L. B.; Zandomeneghi, G.; Meier, B. H.; Bläser, D.; Boese, R.; Schweizer, W. B.; Gilmour, R.; Dunitz, J. D. Angew. Chem. Ind. Ed. 2010, 49, 4503.

9. André, V.; Hardeman, A.; Halasz, I.; Stein, R. S.; Jackson, G. J.; Reid, D. G.; Duer, M. J.; Curfs, C.; Duarte, M. T.; Friščić, T. Angew. Chem. Ind. Ed. 2011, 50, 7858.

10. (a) Užarević, K.; Halasz, I.; Đilović, I.; Bregović, N.; Rubčić, M.; MatkovićČalogović, D.; Tomišić, V. Angew. Chem Int. Ed. 2013, 52, 5504; (b) Caira, M. R.; Nassimbeni, L. R.; Wildervanck, A. F. J. Chem. Soc. Perkin Trans. 1, 1995, 2, 2213.

11. Sridhar, B.; Nanubolu, J. B.; Ravikumar, K. Acta Cryst. 2015, C71, 128.

12. TOPAS, version 4.2, Bruker-AXS, Karlsruhe, Germany.

13. Willmott, P. R.; Meister, D.; Leake, S. J.; Lange, M.; Bergamaschi, A.; Böge, M.; Calvi, M.; Cancellieri, C.; Casati, N.; Cervellino, A.; Chen, Q.; David, C.; Flechsig, U.; Gozzo, F.; Henrich, B.; Jäggi-Spielmann, S.; Jakob, B.; Kalichava, I.; Karvinen, P.; Krempasky, J.; Lüdeke, A.; Lüscher, R.; Maag, S.; Quitmann, C.; Reinle-Schmitt, M. L.; Schmidt, T.; Schmitt, B.; Streun, A.; Vartiainen, I.; Vitins, M.; Wang, X.; Wullschlegera, R. J. Synchrotron Radiat. 2013, 20, 667. 
14. Kazantsev, A. V.; Karamertzanis, P. G.; Adjiman C. S.; Pantelides, C. C. J. Chem. Theory Comput.. 2011, 7, 1998.

15. Frisch, M. J.; Trucks, G. W.; Schlegel, H. B.; Scuseria, G. E.; Robb, M. A.; Cheeseman, J. R.; Scalmani, G.; Barone, V.; Mennucci, B.; Petersson, G. A.; Nakatsuji, H.; Caricato, M.; Li, X.; Hratchian, H. P.; Izmaylov, A. F.; Bloino, J.; Zheng, G.; Sonnenberg, J. L.; Hada, M.; Ehara, M.; Toyota, K.; Fukuda, R.; Hasegawa, J.; Ishida, M.; Nakajima, T.; Honda, Y.; Kitao, O.; Nakai, H.; Vreven, T.; Montgomery, J. A., Jr.; Peralta, J. E.; Ogliaro, F.; Bearpark, M.; Heyd, J. J.; Brothers, E.; Kudin, K. N.; Staroverov, V. N.; Kobayashi, R.; Normand, J.; Raghavachari, K.; Rendell, A.; Burant, J. C.; Iyengar, S. S.; Tomasi, J.; Cossi, M.; Rega, N.; Millam, J. M.; Klene, M.; Knox, J. E.; Cross, J. B.; Bakken, V.; Adamo, C.; Jaramillo, J.; Gomperts, R.; Stratmann, R. E.; Yazyev, O.; Austin, A. J.; Cammi, R.; Pomelli, C.; Ochterski, J. W.; Martin, R. L.; Morokuma, K.; Zakrzewski, V. G.; Voth, G. A.; Salvador, P.; Dannenberg, J. J.; Dapprich, S.; Daniels, A. D.; Farkas, Ö.; Foresman, J. B.; Ortiz, J. V.; Cioslowski, J.; Fox, D. J. Gaussian 09, Revision A.02, Gaussian Inc. Wallingford CT, 2009.

16. Price, S. L.; Leslie, M.; Welch, G. W. A.; Habgood, M.; Price, L. S.; Karamertzanis P. G.; Day, G. M. Phys. Chem. Chem. Phys. 2010, $12,8478$.

17. (a) Williams, D. E. J. Comput. Chem. 2001, 22, 1154; (b) Pyzer-Knapp, E. O. Ph.D. thesis, University of Cambridge, 2014.

18. Stone, A. J.; Alderton, M. Molecular Physics 1985, 56, 1047. 
19. Cooper, T. G.; Hejczyk, K. E.; Jones W.; Day, G. M. J. Chem. Theory Comput. 2008, 4, 1795.

20. Day, G. M.; Price S. L.; Leslie, M. J. Phys. Chem. B 2003, 107, 10919.

21. Nyman J.; Day, G. M. CrystEngComm 2015, 17, 5154.

22. Ghose,R.; Dey, K. Acta Chim. Acad. Sci. Hung. 1981, 108, 9.

23. STARe Software V.9.01., MettlerToledo GmbH, 2006.

24. (a) McCrone, W. C. In Physics and Chemistry of the Organic Solid State; Fox, D.; Labes, M. M.; Weissberger, A., Eds. Wiley Interscience: New York, 1965; Vol. 2, pp 725-767. (b) Threlfall, T. L. Analyst 1995, 120, 2435; (c) Bernstein, J.; Henck, J. O., Cryst. Eng. 1998, 1, 119; (d) Bernstein, J. Polymorphism in Molecular Crystals; Oxford University Press: Oxford, 2002.

25. (a) Bernstein, J. Cryst. Growth Des. 2011, 11. 632; (b) Price, S., Chem. Soc. Rev. 2013, 43, 2098; (c) Desiraju, G. R. Cryst. Growth Des. 2008, 8, 3; (d) Nangia, A., Acc. Chem. Res. 2008, 41 , 595; (e) Brog, J.-P.; Chanez, C.-L.; Crochet, A.; Fromm, K. M., RSC Advances 2013, 3, 1690; (f) Cruz-Cabeza, A. J.; Bernstein, J., Chem. Rev. 2014, 114, 2170 5. (g) Cruz-Cabeza, A. J.; Reutzel-Edens, S. M.; Bernstein, J., Chem. Soc. Rev. 2015, 44, 8619; (h) Bučar, D.-K.; Lancaster, R. W.; Bernstein, J. Angew. Chem. Int. Ed. 2015, 54, 6972.

26. (a) Moulton, B.: Zaworotko, M. J. Chem. Rev. 2001, 101, 1629; (b) Desiraju, G. R.; Vittal, J. J.; Ramanan, A. in Crystal engineering: A textbook, World 
Scientific, New Jersey, 2011; (c) Davey, R. J.; Blagden, N.; Potts, G. D.; Docherty, R., J. Am. Chem. Soc. 1997, 119, 1767.

27. Bučar, D.-K.; Elliott, J. A.; Eddleston, M. D.; Cockcroft, J. K.; Jones, W. Angew. Chem. Int. Ed. 2015, 54, 249.

28. (a) Maher, A.; Rasmuson, A. C.; Croker, D. M.; Hodnett, B. K., J. Chem. Eng. Data 2012, 57, 3525; (b) Liu, J.; Svard, M.; Hippen, P.; Rasmuson, A. C., J. Pharm. Sci. 2015, 104, 2183; (c) Lang, P.; Kiss, V.; Ambrus, R.; Farkas, G.; Szabo-Revesz, P.; Aigner, Z.; Varkonyi, E., J. Pharm. Biomed. Anal. 2013, 84, 177; (d) Brittain, H. G.; Grant, D. J. R.; Myrdal, P. B. Drugs Pharm. Sci. 2009, $192,436$.

29. (a) Davey, R. Y. Chem. Commun. 2003, 1463; (b) Thayer, A. M. Chem. Eng. News 2007, 17; (c) Trask, A. V. Mol. Pharm. 2007, 4, 301; (d) Cabri, W.; Ghetti, P.; Pozzi, G.; Alpegiani, M. Org. Process Res. Dev. 2007, 11, 64; (e) Lee, A. Y.; Erdemir, D.; Myerson, A. S. Annu. Rev. Chem. Biomol. Eng. 2011, 2, 259; (f) Bauer, J.; Spanton, S.; Henry, R.; Quick, J.; Dziki, W.; Porter, W.; Morris, J. Pharm. Res. 2001, 18, 859.

30. (a) Polymorphism in pharmaceutical solids 2nd ed, Brittain, G. R., Ed., Informa Healthcare USA Inc.. New York, NY, 2009; (b) Bryn, S. R.; Pfeiffer, R. R.; Stowell, J. G. in Solid-State Chemistry of Drugs, SSCI, West Lafayette, IN, 1999; (c) Solid-State Characterization of Pharmaceuticals; Zakrzewski, A.; Zakrzewski, M., Eds. Assa International Inc.: Danbury, CT, USA, 2006; (d) Polymorphism in 
the Pharmaceutical Industry; Hilfiker, R., Ed. Wiley-VCH: Weinheim, Germany, 2006;

31. (a) Etter, M. C.; MacDonald, J. C.; Bernstein, J. Acta Cryst. 1990, B46, 256; (b) Bernstein, J.; Davis, R. E.; Shimoni, L.; Chang, N. Angew. Chem. Int. Ed. Engl. 1995, 34, 1555.

32. Kelly, R. E. A.; Lee, Y. J.; Kantorovich, L. N. J. Phys. Chem. B, 2005, 109, 11933.

33. Coquerel, G. Chem. Eng. Process. 2006, 45, 857.

34. Halasz, I. Cryst. Growth Des. 2010, 10, 2817.

35. (a) Furukawa, M.; Tanaka, H.; Kawai, T. Surf. Sci. 2000, 445, L58; (b) Furukawa, M.; Tanaka, H.; Kawai, T. Surf. Sci. 2000, 445, 1; (c) Sowerby, S. J.; Edelwirth, M.; Heckl, W. M. J. Phys. Chem. B 1998, 102, 5914; (d) Uchihashi, T.; Okada, T. Phys. Rev. B 1999, 60, 8309; (e) Capitán, M. J.; Álvarez, J.; Wang, Y.; Otero, R.; Alcamí, M.; Martín, F.; Miranda, R. ChemPhysChem 2013, 14, 3294.

36. Freund, J. E.; Edelwirth, M.; Kröbel, P.; Heckl, W. M. Phys. Rev. B, 1997, 55, 5394.

37. Mamdouh, W.; Dong, M.; Kelly, R. E. A.; Kantorovich, L. N.; Besenbacher, F. J. Phys. Chem. B, 2007, 111, 12048.

38. Zhang, F.; Kambara, O.; Tominaga, K.; Nishizawa, J.; Sasaki, T.; Wang, H.-W.; Hayashi, M. RSC $A d v$. 2014, 4, 269. 
39. (a) Models, Mysteries, and Magic of Molecules, Boeyens J. C.; Ogilvie, J. F, Eds., Springer Netherlands, 2007; (b) Desiraju, G. R. CrystEngComm, 2007, 9, 91.

40. (a) Anderson, K. M.; Steed, J. W. CrystEngComm, 2007, 9, 328.

41. (a) Bernstein, J.; Dunitz, J. D.; Gavezotti, A. Cryst. Growth Des. 2008, 8, 2011;

(b) Anderson, K. M.; Probert, M. R.; Goeta, A. E.; Steed, J. W., CrystEngComm 2011, 13, 83 .

42. (a) Jarring, K.; Larsson, T.; Stensland, B.; Ymén, I. J. Pharm. Sci. 2006, 95, 1144; (b) Stahly, G. P. Cryst. Growth Des. 2007, 7, 1007; (c) Rubčić, M.; Užarević, K.; Halasz, I.; Bregović, N.; Mališ, M.; Đilović, I.; Kokan, Z.; Stein, R. S.; Dinnebier, R. E.; Tomišić, V. Chem. Eur. J. 2012, 18, 5620.

43. Bernstein, J.; Davey, R. J.; Henck J.O. Angew. Chem. Int. Ed. 1999, 38, 3440. 


\title{
Solid-state chemistry and polymorphism of the nucleobase adenine
}

\author{
Tomislav Stolar, Stipe Lukin, Josip Požar, Mirta Rubčić, Graeme M. Day, Ivana Biljan, \\ Dubravka Šišak Jung, Gordan Horvat, Krunoslav Užarević, Ernest Meštrović, \\ and Ivan Halasz
}

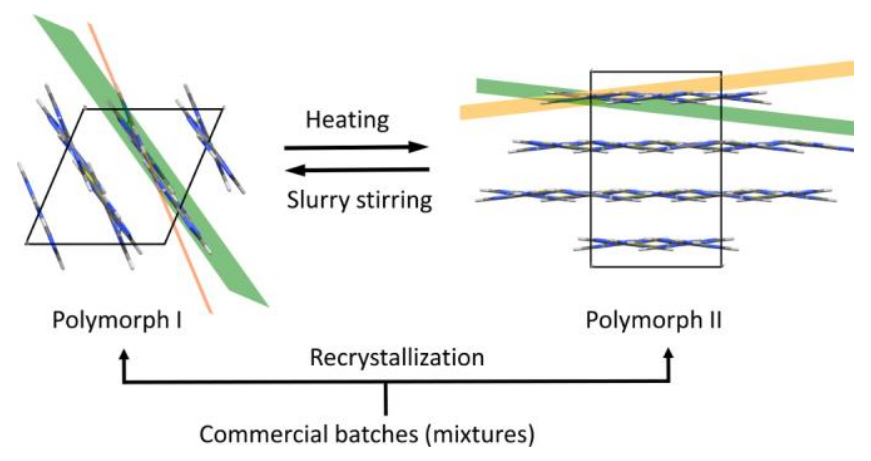

Despite numerous studies and uses of the nucleobase adenine, its solid-state chemistry has remained largely unexplored. Here we describe a second polymorph of adenine, determine its relationship to the first polymorph using ab initio theoretical calculations and experimental thermodynamics and note that adenine is most often marketed as the mixture of the two polymorphs. 